\title{
Erratum to: Relationship among soil management, organic matter content and root development along the explorable soil profile in the vineyard
}

Alberto Vercesi ${ }^{1}$, Matteo Gatti ${ }^{1}$, Claudia Meisina ${ }^{2}$, Massimiliano Bordoni ${ }^{2}$, Michael Maerker ${ }^{2}$, Cristina Ganimede $^{1}$, Maria Cristina Reguzzi $^{1}$, Emanuele Mazzoni ${ }^{1}$, and Stefano Poni ${ }^{2}$

${ }^{1}$ DI.PRO.VE.S. Department of Sustainable Crop Production, Università Cattolica del Sacro Cuore, Via Emilia Parmense 84, 29122 Piacenza (PC), Italy

${ }^{2}$ Dipartimento di Scienze della terra e dell'ambiente, Università di Pavia, Italy

Original article: BIO Web of Conferences 13, 04021 (2019), https://doi.org/10.1051/bioconf/20191304021

Figure 1 should be replaced by the following Figure:

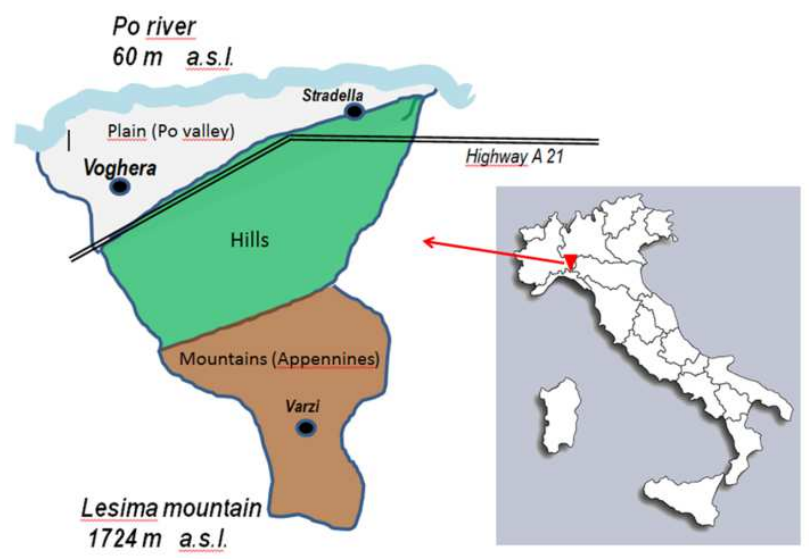

Figure 2 should be replaced by the following Figure:

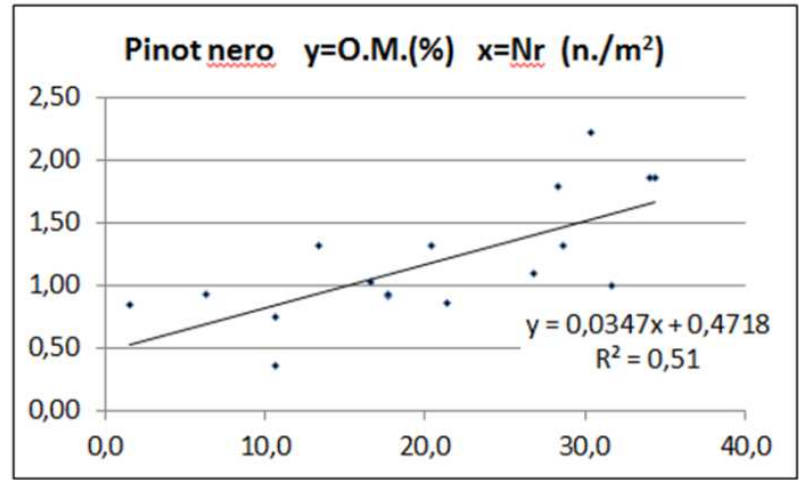

